\title{
A RANDOMISED DOUBLE-BLIND CLINICAL TRIAL COMPARING ISOBARIC ROPIVACAINE 0.5\% WITH DEXAMETHASONE AND 0.75\% ROPIVACAINE ALONE IN SPINAL ANAESTHESIA IN TRANSURETHRAL RESECTION OF PROSTATE CASES
}

\author{
Dhanashree Kale1, Vithal K. Dhulkhed², Shraddha Naik3, Ghanashyam Jadhav4, Naseema Kanase 5
}

${ }^{1}$ Assistant Professor, Department of Anaesthesiology, Krishna Institute of Medical Sciences, Deemed University, Karad. ${ }^{2}$ Professor and HOD, Department of Anaesthesiology, Krishna Institute of Medical Sciences, Deemed University, Karad. ${ }^{3}$ Assistant Professor, Department of Anaesthesiology, Krishna Institute of Medical Sciences, Deemed University, Karad. ${ }^{4}$ Senior Resident, Department of Anaesthesiology, Krishna Institute of Medical Sciences, Deemed University, Karad. ${ }^{5}$ Professor, Department of Anaesthesiology, Krishna Institute of Medical Sciences, Deemed University, Karad.

ABSTRACT

\section{BACKGROUND}

This clinical study was designed to evaluate the clinical efficacy and safety of lower concentration of ropivacaine i.e. intrathecal $0.5 \%$ isobaric ropivacaine with dexamethasone for transurethral resection of prostate (TURP) in elderly patients. This combination should provide better haemodynamic stability and prolonged postoperative analgesia compared with $0.75 \%$ plain ropivacaine.

\section{MATERIALS AND METHODS}

Eighty patients were randomly divided into two groups, each comprising of 40 patients. Subarachnoid block was performed using $3.5 \mathrm{~mL}$ isobaric Ropivacaine $0.5 \%$ with $1 \mathrm{~mL}$ Dexamethasone ( $4 \mathrm{mg}$ ) in group I (RD) and $3.5 \mathrm{~mL}$ isobaric Ropivacaine $0.75 \%$ with 1 $\mathrm{mL}$ normal saline in group II (R). Haemodynamic parameters, onset and total duration of sensory and motor block, time to reach maximum sensory block, duration of sensory and motor block at T10, postoperative analgesic requirements and adverse effects were recorded.

\section{RESULTS}

Group RD shows longer onset of sensory blockade was $2.30 \pm 0.56$ minutes compared to $1.58 \pm 0.64$ minutes in group- $\mathrm{R}$ ( $\mathrm{P}<0.001$ ) and motor blockade $2.23 \pm 0.70$ minutes compared to $1.68 \pm 0.694$ minutes in group $-\mathrm{R}(\mathrm{P}<=0.001)$. The median time to reach the highest level of analgesia was $19.05 \pm 6.02$ minutes in group RD; $16.05 \pm 4.68$ in group $\mathrm{R}$. The duration of sensory level at T10 dermatome was prolonged i.e. $90.60 \pm 38.90$ minutes in group- $\mathrm{R}$ compared to $47.45 \pm 13.81$ minutes in group- $\mathrm{RD}(\mathrm{P}<0.001)$. Total duration of sensory block was prolonged in group R i.e. $188.75 \pm 20.68$ compared to $155.38 \pm 28.10$ in group $\mathrm{RD}(\mathrm{P}<0.001)$. The duration of motor blockade in group-RD was $118.00 \pm 13.24$ minutes compared to $154.75 \pm 20.88$ minutes in group- $\mathrm{R}$ ( $\mathrm{P}<0.001$ ). The time of first request of analgesics in group-RD was $293.08 \pm 28.26$ minutes compared to $267.95 \pm 30.52$ minutes in group- $\mathrm{R}$ (P $=0.000$ ). The total opioid consumption within 24 hours following surgery in group-I was $77.50 \pm 31.92$ milligrams compared to $102.50 \pm 35.72$ milligrams in group- $\mathrm{R}(\mathrm{P}<0.001)$.

\section{CONCLUSION}

Ropivacaine $0.5 \%$ with dexamethasone produces adequate surgical anaesthesia for TURP surgeries with negligible haemodynamic disturbances and prolongs the time to first request for analgesia and lesser opioid consumption following surgery.

\section{KEYWORDS}

Elderly Patients, Ropivacaine, Dexamethasone, Subarachnoid Block, Transurethral Resection of Prostate.

HOW TO CITE THIS ARTICLE: Kale D, Dhulkhed VK, Naik S, et al. A randomised double-blind clinical trial comparing isobaric ropivacaine $0.5 \%$ with dexamethasone and $0.75 \%$ ropivacaine alone in spinal anaesthesia in trans urethral resection of prostate cases. J. Evolution Med. Dent. Sci. 2017;6(81):5687-5691, DOI: 10.14260/Jemds/2017/1234

\section{BACKGROUND}

This clinical study was designed to evaluate the clinical efficacy and safety of lower concentration of ropivacaine i.e. intrathecal $0.5 \%$ isobaric ropivacaine with dexamethasone for transurethral resection of prostate (TURP) in elderly patients. Low dose ropivacaine provides a high degree of

Financial or Other, Competing Interest: None.

Submission 15-04-2017, Peer Review 19-06-2017,

Acceptance 23-06-2017, Published 09-10-2017.

Corresponding Author:

Dr. Dhanashree Kale,

Assistant Professor

Department of Anaesthesiology

Krishna Institute of Medical Sciences,

Deemed University, Karad.

E-mail: dhanashree_kale02@yahoo.com

DOI: $10.14260 /$ jemds/2017/1234

\section{(c) (i) $(9)$}

haemodynamic stability and low incidence of hypotension and bradycardia. ${ }^{1}$ Ageing and disease make elderly patients susceptible to hypotension during anaesthesia as these patients have a relatively high prevalence of coexisting systemic diseases. Benign prostatic hypertrophy frequently leads to symptomatic bladder outlet obstruction in older men. Recent clinical data have shown that ropivacaine is clinically effective and safe for regional anaesthetic techniques with good tolerability. ${ }^{2}$ Ropivacaine could provide adequate surgical anaesthesia without compromising early ambulation and discharge. ${ }^{2}$ Corticosteroids have been studied recently as adjuncts to local anaesthetics in regional block. $^{3}$

Ropivacaine is less lipophilic than bupivacaine and is associated with decreased potential for central nervous system toxicity and cardiotoxicity. ${ }^{4}$ Dexamethasone relieves pain by reducing inflammation and blocking transmission of nociceptive C-fibres and by suppressing ectopic neural 
discharge. It has been shown that the duration of postoperative analgesia was prolonged when dexamethasone is given as an adjunct for peripheral nerve blocks. ${ }^{5}$

Intrathecal dexamethasone may influence intraspinal prostaglandin production. Acute noxious stimulation of peripheral tissues leads to sensitisation of dorsal horn neurons of the spinal cord by the release of substances such as glutamate and aspartate. ${ }^{6}$

Ropivacaine is less lipid-soluble than bupivacaine and is reported to be $20 \%$ less potent than bupivacaine at equal doses. ${ }^{7}$ Ropivacaine produces less motor blockade and is of shorter duration than bupivacaine. ${ }^{8,9}$ This clinical study was designed to evaluate the clinical efficacy and safety of lower concentration of ropivacaine i.e. intrathecal $0.5 \%$ isobaric ropivacaine with dexamethasone for transurethral resection of prostate (TURP) in elderly patients. This combination should provide better haemodynamic stability and prolonged postoperative analgesia compared with $0.75 \%$ plain ropivacaine.

\section{MATERIALS AND METHODS}

This double-blind randomised clinical study was conducted on 80 male adult patients of physical status ASA grade I-II, aged 45-75 years with body weight $45-85 \mathrm{~kg}$ and height $145-$ $180 \mathrm{~cm}$, scheduled for TURP under subarachnoid block. After approval of Institutional Ethical Committee and written informed consent, all patients were subjected to preanaesthetic assessment. Patients with severe cardiac or pulmonary diseases, neurologic or renal dysfunction, bleeding or coagulation disorder, allergy to local anaesthetic amides, deformed spinal column, infection at site of lumbar puncture, or refusal to technique were excluded from the study. The patients were randomised into two groups, according to computer-generated numbers. Group RD receiving intrathecal Ropivacaine $0.5 \% \quad 3.5 \mathrm{~mL}$ with Dexamethasone $4 \mathrm{mg} 1 \mathrm{~mL}$ (Total volume $=4.5 \mathrm{~mL}$ ) and Group R receiving intrathecal Ropivacaine $0.75 \% 3.5 \mathrm{~mL}$ with Normal Saline $1 \mathrm{~mL}$. (Total volume $=4.5 \mathrm{~mL}$ ).

All patients received tablet Diazepam $5 \mathrm{mg}$ orally day before surgery for anxiolysis with sips of water. In the operating room, noninvasive blood pressure, $\mathrm{SpO}_{2}$, ECG leads were connected to the patient. Pre-operative baseline systolic and diastolic $\mathrm{BP}, \mathrm{PR}, \mathrm{SpO}_{2}$ and $\mathrm{RR}$ were recorded. Under aseptic precautions a midline lumbar puncture was performed at L3-L4 interspace using a 25G Quincke needle in lateral position. Following free flow of clear CSF, anaesthetic solution was injected slowly in both the groups. Then, the patient was placed in supine position.

The time of intrathecal injection was considered as 0 and following parameters were observed. After intrathecal injection, assessment started immediately and continued every 15 seconds till loss of pinprick sensation at T10 level. Assessment of sensory block was done by loss of sensation to pinprick using $23 \mathrm{G}$ sterile needle. Onset time was taken from intrathecal injection to loss of pinprick sensation at T10. The maximum sensory level achieved following intrathecal injection of drug was measured when dermatomal level of sensory block remains same at successive two points of time. Time to achieve maximal sensory block i.e. time taken from intrathecal injection of drug to loss of pinprick sensation at highest dermatomal level was noted. Time taken from onset of sensory blockade till time of complete return of sensations at T10 level was noted as duration of sensory block at T10. Time from intrathecal injection of drug to complete return of sensations was noted as total duration of sensory block. Patients whose sensory block reached T10 were allowed to start the surgery. Motor block was assessed by Bromage score. [ 0 = No paralysis; 1 = Inability to raise extended leg; 2 = Inability to flex the knee; 3 = Inability to flex the ankle (complete motor block)]. Assessment started immediately after the intrathecal injection, tested every 15 seconds till Bromage score of 3 . Onset of motor block was taken to achieve Bromage score 3 from the time of intrathecal injection. Duration of motor block was taken as time from intrathecal injection to return of Bromage score 0.

Haemodynamic parameters i.e. heart rate, arterial blood pressure, and $\mathrm{SpO}_{2}$ were recorded before the intrathecal injection and thereafter at every $2 \mathrm{~min}$. during the first 10 min., and then every $15 \mathrm{~min}$. in the first hour and every 20 min. until the patient was transferred to the post-anaesthesia room. Tramadol was administered when the patient complained of pain. Time of first request for post-operative analgesia and total opioid consumption in first 24 hours by the patient was noted. The side effects like shivering, high spinal blockade, breathing difficulty, nausea and vomiting were looked for and occurrence of haemodynamic disturbances like hypotension, bradycardia were noted. Hypotension was defined as fall in systolic BP $>30 \%$ from baseline or MAP $<60 \mathrm{~mm}$ of $\mathrm{Hg}$. This was managed with Inj. Ephedrine $6 \mathrm{mg}$ IV increments. Bradycardia was defined as heart rate $<60 / \mathrm{min}$. and this was managed with Inj. Atropine $0.01 \mathrm{mg} / \mathrm{kg}$ IV. Respiratory depression defined as $\mathrm{RR}<8 / \mathrm{min}$. and or $\mathrm{SpO}_{2}<85 \%$. This was planned to be managed with bag and mask ventilation or intubation and IPPV if necessary.

\section{Statistical Analysis}

For detecting a mean difference of 30 minutes with pooled standard deviation (SD) of 20 minutes in the duration of sensory block which we considered as clinically useful after conducting a pilot study, for alpha value of 0.01 and power 95\%; the sample size calculated was minimum 16 per group. But, however, we included 40 patients in each group. The categorical factors are represented by the number and frequency (\%) of cases. The continuous variables are represented by measures of central frequency (like mean, median and mode) and deviation (Standard Deviation and range).

SPSS 14.0 version was used for statistics. Independent student's t-test, Mann-Whitney test and Fisher's exact test, unpaired and paired t-test were used for quantitative nominal data (mean +/-). For repeated haemodynamic data, we used General Linear Model (GLM). Categorical data were compared by using $\chi^{2}$ and Mann-Whitney $U$ test where appropriate. $P$ value of $<0.05$ was considered significant.

\section{RESULTS}

Patients studied across the group did not vary much with respect to age, height or weight (Table 1). Heart rate, systolic and diastolic blood pressure in both the groups did not vary significantly (Table 3). The onset of sensory blockade in group $\mathrm{RD}$ was $2.30 \pm 0.56$ minutes compared to $1.58 \pm 0.64$ minutes in group $\mathrm{R}$ which was statistically significant $\mathrm{P}<$ 0.001). Similarly, the onset of motor blockade in group-RD was $2.23 \pm 0.70$ minutes compared to $1.68 \pm 0.74$ minutes in 
group- $\mathrm{R}$ which was also statistically significant $(\mathrm{P}=0.001)$. The median time to reach the highest level of analgesia was less than $20 \mathrm{~min}$. in both groups (ropivacaine $0.5 \%$ group, $19.05 \pm 6.02$ min.; ropivacaine $0.75 \%$ group, $16.05 \pm 4.68$ min.), the duration of sensory level at T10 dermatome in group-RD was $47.45 \pm 13.81$ minutes compared to $90.60 \pm$ 38.90 minutes in group- $\mathrm{R}$ which was statistically highly significant $(\mathrm{P}<0.001)$.The total duration of sensory block was prolonged in group R; $188.75 \pm 20.68$ compared to $155.38 \pm$ 28.10 in group $\mathrm{RD}$, which was statistically significant $(\mathrm{P}<0.001)$.The duration of motor blockade in group-RD was $118.00 \pm 13.24$ minutes compared to $154.75 \pm 20.88$ minutes in group- $\mathrm{R}$ which was significant $(\mathrm{P}<0.001)$. (Table 2$)$.

The time of first request of analgesics in group-RD was $293.08 \pm 28.26$ minutes compared to $267.95 \pm 30.52$ minutes in group- $\mathrm{R}$ statistically significant $(\mathrm{P}=0.003)$. Addition of dexamethasone to $0.5 \%$ Ropivacaine has increased its period of analgesia compared to $0.75 \%$ Ropivacaine and prolonged the time to first request of postoperative analgesia. The total opioid (Tramadol) consumption within 24 hours following surgery in group-RD was $77.50 \pm 31.92 \mathrm{mg}$ compared to $102.50 \pm 35.72 \mathrm{mg}$ in group-R (Table 4) which was statistically significant $(\mathrm{P}=0.001)$. This shows that requirement of opioid analgesia was significantly reduced due to addition of dexamethasone to $0.5 \%$ Ropivacaine compared to $0.75 \%$ Ropivacaine. In both the groups, surgery was accomplished without requisition for additional anaesthetic.

Six patients had shivering in group $-\mathrm{RD}$ as compared to 8 patients in group-R. One patient in each group had bradycardia. There were no incidences of post-dural puncture headache, nausea or vomiting in both groups.

\begin{tabular}{|c|c|c|c|c|}
\hline $\begin{array}{c}\text { Demographic } \\
\text { Parameters }\end{array}$ & $\begin{array}{c}\text { Group } \\
\text { RD }\end{array}$ & $\begin{array}{c}\text { Group } \\
\text { R }\end{array}$ & $\begin{array}{c}\text { Mean } \\
\text { Difference }\end{array}$ & P value \\
\hline Age & $63.12 \pm 7.56$ & $60.3 \pm 8.01$ & 2.8 & 0.108 \\
\hline Height & $\begin{array}{c}162.25 \pm \\
8.86\end{array}$ & $\begin{array}{c}164.25 \pm \\
8.84\end{array}$ & 2.0 & 0.315 \\
\hline Weight & $64.40 \pm 8.41$ & $65.10 \pm 7.07$ & 0.7 & 0.688 \\
\hline Table 1. Comparison of Demographic Parameters in Two \\
Groups of Patients Studied \\
\hline
\end{tabular}

\begin{tabular}{|c|c|c|c|c|}
\hline Criteria & $\begin{array}{c}\text { Group } \\
\text { RD }\end{array}$ & $\begin{array}{c}\text { Group } \\
\text { R }\end{array}$ & $\begin{array}{c}\text { Mean } \\
\text { Difference }\end{array}$ & $\begin{array}{c}\text { P } \\
\text { value }\end{array}$ \\
\hline Sensory Block & & & & \\
\hline Onset & $\begin{array}{c}2.30 \pm \\
0.56\end{array}$ & $\begin{array}{c}1.58 \pm \\
0.64\end{array}$ & 0.72 & $<0.001$ \\
\hline $\begin{array}{c}\text { Time to Maximum } \\
\text { Cephalad Spread }\end{array}$ & $19.05 \pm 6.53$ & $\begin{array}{c}16.05 \pm \\
4.68\end{array}$ & 3.00 & 0.010 \\
\hline Duration at T10 & $\begin{array}{c}47.45 \pm \\
13.81\end{array}$ & $\begin{array}{c}90.60 \pm \\
38.90\end{array}$ & 43.15 & $<0.001$ \\
\hline Total Duration & $\begin{array}{c}155.38 \pm \\
28.10\end{array}$ & $\begin{array}{c}188.75 \pm \\
20.68\end{array}$ & 37.37 & $<0.001$ \\
\hline Motor Block & & & & \\
\hline Onset & $\begin{array}{c}2.23 \pm \\
0.70\end{array}$ & $\begin{array}{c}1.68 \pm \\
0.74\end{array}$ & 0.55 & $<0.001$ \\
\hline Time to Maximum & $13.25 \pm 4.79$ & $\begin{array}{c}12.83 \pm \\
7.98\end{array}$ & 0.42 & 0.774 \\
\hline Degree Block & $\begin{array}{c}118.00 \pm \\
\text { Total Duration }\end{array}$ & $\begin{array}{c}154.75 \pm \\
20.88\end{array}$ & 36.37 & $<0.001$ \\
\hline Table Compan & 13.24 & 20.88 & \\
\hline
\end{tabular}

Table 2. Comparison of Sensory Block and Motor Block Characteristics in Two Groups of Patients Studied

\begin{tabular}{|c|c|c|c|c|}
\hline $\begin{array}{c}\text { Haemodynamic } \\
\text { Parameter }\end{array}$ & \multicolumn{2}{|c|}{ Heart Rate } & \multicolumn{2}{c|}{ Systolic BP } \\
\hline Time Interval & Group RD & Group R & Group RD & Group R \\
\hline \multirow{2}{*}{ Baseline } & $\begin{array}{c}76.45 \pm \\
13.82\end{array}$ & $\begin{array}{c}75.48 \pm \\
8.28\end{array}$ & $\begin{array}{c}126.25 \pm \\
9.68\end{array}$ & $\begin{array}{c}26.30 \pm \\
13.29\end{array}$ \\
\hline \multirow{2}{*}{2 minutes } & $\begin{array}{c}77.48 \pm \\
14.51\end{array}$ & $\begin{array}{c}77.58 \pm \\
9.78\end{array}$ & $\begin{array}{c}125.43 \pm \\
8.87\end{array}$ & $\begin{array}{c}25.45 \pm \\
10.50\end{array}$ \\
& $76.88 \pm$ & $72.58 \pm$ & $125.88 \pm$ & $122.10 \pm$ \\
\multirow{2}{*}{5 minutes } & 11.16 & 8.48 & 10.47 & 11.40 \\
& $77.03 \pm$ & $72.53 \pm$ & $123.63 \pm$ & $119.55 \pm$ \\
\multirow{2}{*}{10 minutes } & 12.54 & 10.01 & 10.44 & 12.73 \\
\hline \multirow{2}{*}{15 minutes } & $75.45 \pm$ & $73.25 \pm$ & $119.95 \pm$ & $114.85 \pm$ \\
& 14.77 & 11.29 & 10.68 & 10.25 \\
\hline \multirow{2}{*}{20 minutes } & $70.08 \pm$ & $72.13 \pm$ & $121.65 \pm$ & $114.03 \pm$ \\
& 13.12 & 13.31 & 14.89 & 9.56 \\
\hline \multirow{2}{*}{30 minutes } & $70.08 \pm$ & $67.63 \pm$ & $119.88 \pm$ & $113.08 \pm$ \\
& 9.48 & 9.81 & 11.88 & 10.24 \\
\hline \multirow{2}{*}{45 minutes } & $72.58 \pm$ & $68.13 \pm$ & $121.60 \pm$ & $114.18 \pm$ \\
& 9.81 & 9.10 & 9.18 & 11.14 \\
\hline \multirow{2}{*}{60 minutes } & $71.95 \pm$ & $69.68 \pm$ & $120.33 \pm$ & $114.93 \pm$ \\
& 10.62 & 9.06 & 9.25 & 10.55 \\
\hline
\end{tabular}

Table 3. Comparison of Haemodynamic Parameters in Two Groups of Patients Studied

\begin{tabular}{|c|c|c|}
\hline Group & $\begin{array}{c}\text { Time of First } \\
\text { Request for } \\
\text { Post-op Analgesia }\end{array}$ & $\begin{array}{c}\text { Total Opioid } \\
\text { (Tramadol) } \\
\text { Consumption (mg) } \\
\text { in 24 hours after } \\
\text { Surgery }\end{array}$ \\
\hline Group RD & $293.08 \pm 28.26$ & $77.50 \pm 31.92$ \\
\hline Group R & $267.95 \pm 30.52$ & $102.50 \pm 35.72$ \\
\hline Mean Difference & 25.13 & 25.00 \\
\hline \multicolumn{2}{|c|}{ Table 4. Comparison of Postoperative Analgesic } \\
Requirements in Two Groups \\
\hline
\end{tabular}

\section{DISCUSSION}

Although dexamethasone has been used intrathecally for many years, it has not been evaluated when it was given in conjunction with ropivacaine intrathecally. This double-blind randomised study was conducted to compare two different concentrations of intrathecal ropivacaine in TURP cases and that low concentration of ropivacaine $(0.5 \%) 3.5 \mathrm{~mL}$ in combination with $4 \mathrm{mg}$ dexamethasone. This double-blind randomised study was conducted to compare two different concentrations of intrathecal ropivacaine in TURP cases, and low concentration of ropivacaine $(0.5 \%) 3.5 \mathrm{~mL}$ in combination with $4 \mathrm{mg}$ dexamethasone $1 \mathrm{~mL}$ is enough to produce sufficient surgical anaesthesia in the patients comparable to $0.75 \%$ ropivacaine $3.5 \mathrm{~mL}$ (total volume 4.5 $\mathrm{mL}$ by adding Normal Saline $1 \mathrm{~mL}$ ). Dexamethasone added to $0.5 \%$ ropivacaine prolonged the time to first analgesic request. It also reduced total opioid (Tramadol) consumption postoperatively as compared to plain ropivacaine $0.75 \%$.

\section{Perioperative Cardiovascular Parameters}

Heart rate, systolic and diastolic blood pressure in both the groups did not vary significantly. Cardiovascular changes were unremarkable throughout, and similar in the two groups, as were the volumes of fluid administered. Kim $S$ Khawet al10 in 2001, found that the incidence of hypotension were similar in a comparison of different doses of plain ropivacaine. John On-Nin Wong et al ${ }^{11}$ in 2004, have observed the same that there are no major cardiovascular changes in 
the two groups receiving plain ropivacaine in different doses compared to each other.

\section{Changes in the Onset of Sensory and Motor Blockade}

In our study, the onset of sensory blockade in group-RD was $2.30 \pm 0.56$ minutes compared to $1.58 \pm 0.64$ minutes in group-R with mean difference of 0.72 minutes which was statistically significant $(\mathrm{P}<0.001)$. Similarly, the onset of motor blockade in group-RD was $2.23 \pm 0.70$ minutes compared to $1.68 \pm 0.74$ minutes in group- $\mathrm{R}$ with mean difference of 0.55 minutes which was also statistically significant $(\mathrm{P}=0.001)$. The median time to reach the highest level of analgesia was less than $20 \mathrm{~min}$. in both groups with mean difference of 3.00 minutes. Ying Y. Lee et al ${ }^{12}$ in 2007 found that the onset of motor blockade was more reliable with $0.75 \%$ ropivacaine.

\section{Duration of Sensory Block}

In our study, the duration of sensory level at T10 dermatome in group-RD was $47.45 \pm 13.81$ minutes compared to $90.60 \pm$ 38.90 minutes in group- $\mathrm{R}$ with mean difference of 43.15 minutes which was statistically significant $(\mathrm{P}<0.001)$. The total duration of sensory block was prolonged in group $\mathrm{R}$; $188.75 \pm 20.68$ compared to $155.38 \pm 28.10$ in group RD, with mean difference of 37.37 minutes which was statistically significant $(\mathrm{P}<0.001)$. Jack $\mathrm{W}$ van Kleef et al ${ }^{4}$ in 1994 , found that the duration of analgesia at the level of T12 was significantly longer in the $0.75 \%$ group as compared to $0.5 \%$ group. However, the total duration of analgesia was clearly dose-dependent $(\mathrm{P}<0.002)$, lasting longer with the more concentrated solution. This shows that ropivacaine $0.75 \%$ has a more reliable duration of analgesia.

\section{Duration of Motor Blockade}

In our study, the duration of motor blockade in group-RD was $118.00 \pm 13.24$ minutes compared to $154.75 \pm 20.88$ minutes in group- $\mathrm{R}$ with mean difference of 36.37 minutes which was significant $(\mathrm{P}<0.001)$. Ropivacaine $0.75 \%$ solution resulted in longer duration of motor block. Van Kleef, Jack $W$ et al ${ }^{4}$ in 1994 observed that the greater propensity to produce a complete motor block, and the longer duration of analgesia and motor block produced by the $0.75 \%$ ropivacaine solution, should be suitable for orthopaedic and vascular surgical procedures of intermediate duration, requiring an intense motor block. On the other hand, the $0.5 \%$ ropivacaine solution with its shorter duration of analgesia and often relatively moderate motor block could be useful for transurethral procedures where the degree of motor block is not of critical importance. ${ }^{4}$

\section{Time of First Request of Analgesics}

In our study, the time of first request of analgesics in group$\mathrm{RD}$ was $293.08 \pm 28.26$ minutes compared to $267.95 \pm 30.52$ minutes in group- $\mathrm{R}$ with mean difference of 25.13 minutes which was significant $(P=0.003)$. Jack $W$. van Kleef et $\mathrm{al}^{4}{ }^{4}$ in 1994 , found that the time of first request for analgesia was significantly longer in the $0.75 \%$ group as compared to group RD. This shows that there was significantly longer period of analgesia with $0.75 \%$ ropivacaine. Our study has found that addition of dexamethasone to $0.5 \%$ ropivacaine has increased its period of analgesia compared to $0.75 \%$ ropivacaine and prolonged the time to first request of post-operative analgesia.
Total Opioid (Tramadol) Consumption in 24 hours following Surgery

In our study, the total opioid (Tramadol) consumption within 24 hours following surgery in group-RD was $77.50 \pm 31.92$ mg compared to $102.50 \pm 35.72 \mathrm{mg}$ in group- $\mathrm{R}$ with mean difference of $25 \mathrm{mg}$ which was statistically highly significant $(\mathrm{P}=0.001)$. This shows that requirement of opioid (Tramadol) analgesia was significantly reduced due to addition of dexamethasone to $0.5 \%$ ropivacaine compared to $0.75 \%$ ropivacaine.

Elzayyat $\mathrm{N}$ et $\mathrm{al}^{13}$ in 2014 found that compared to bupivacaine with dexmedetomidine, bupivacaine with dexamethasone had significantly longer duration of sensory block $(\mathrm{P}=0.025)$ and longer duration of postoperative analgesia $(\mathrm{P}<0.001)$. Compared with plain bupivacaine, bupivacaine with dexamethasone had significantly longer duration of sensory block $(\mathrm{P}<0.001)$ and longer duration of postoperative analgesia $(\mathrm{P}<0.001)$.

Biradar et $\mathrm{al}^{14}$ found that addition of dexamethasone to $1.5 \%$ lidocaine with adrenaline in supraclavicular brachial plexus block speeds the onset and prolongs the duration of sensory and motor blockade.

\section{Adverse Effects}

Six patients had shivering in group RD as compared to 8 patients in group $R$. One patient in each group had bradycardia. There were no incidences of post-dural puncture headache, nausea or vomiting in both groups. Wong J. et al11 al in 2004 found that the incidence of shivering was more in the group receiving $33.75 \mathrm{mg}$ plain ropivacaine than the group receiving $26.25 \mathrm{mg}$ of plain ropivacaine. We found no major differences clinically in the adverse effects of both drugs.

\section{CONCLUSION}

Although intrathecal administration of $0.75 \%$ isobaric ropivacaine produces longer duration of sensory and motor block compared to isobaric $0.5 \%$ ropivacaine with dexamethasone; $0.5 \%$ ropivacaine with dexamethasone produces adequate surgical anaesthesia for TURP surgeries with negligible haemodynamic disturbances and found to prolong the time to first request for analgesia and lessen opioid consumption following surgery.

\section{REFERENCES}

[1] McNamee DA, McClelland AM, Scott S, et al. Spinal anaesthesia: comparison of plain ropivacaine $5 \mathrm{mg}$ $\mathrm{ml}(-1)$ with bupivacaine $5 \mathrm{mg} \mathrm{ml}(-1)$ for major orthopaedic surgery. Br J Anaesth 2002;89(5):702-6.

[2] Gupta K, Singhal AB, Gupta PK, et al. Ropivacaine: anesthetic consideration in elderly patients for transurethral resection of prostate a clinical trial. Anesth Essays Res 2013;7(2):178-82.

[3] Bani-Hashem N, Hassan-Nasab B, Pour EA, et al. Addition of intrathecal dexamethasone to bupivacaine for spinal anesthesia in orthopedic surgery. Saudi J Anaesth 2011;5(4):382-6. 
[4] van Kleef JW, Veering BT, Burm AGL. Spinal anaesthesia with ropivacaine: A double blind study on the efficacy and safety of $0.5 \%$ and $0.75 \%$ solutions in patients undergoing minor lower limb surgery. Anaesth Analg 1994;78(6):1125-30.

[5] Iyer CP, Ross L, Joshi G, et al. Efficacy of ropivacaine with or without dexamethasone for enhancing extremity nerve blocks. Reg Anesth Pain Med 2005;30:A42.

[6] Abram SE, Marsala M, Yaksh TL. Analgesic and neurotoxic effects of intrathecal corticosteroids in rats. Anesthesiology 1994;81(5):1198-205.

[7] Polley LS, Columb MO, Naughton NN, et al. Relative analgesic potencies of ropivacaine and bupivacaine for epidural analgesia in labor: implications for therapeutic indexes. Anesthesiology 1999;90(4):94450 .

[8] Scott DB, Lee A, Fagan D, et al. Acute toxicity of ropivacaine compared with that of bupivacaine. Anesth Analg 1989;69(5):563-9.

[9] Markham A, Faulds D. Ropivacaine. A review of its pharmacology and therapeutic use in regional anaesthesia. Drugs 1996;52(3):429-49.
[10] Khaw KS, Kee NWD, Wong EL, et al. Spinal ropivacaine for cesarean section: a dose-finding study. Anesthesiology 2001;95(6):1346-50.

[11] Wong JO, Tan TD, Leung PO, et al. Comparison of the effect of two different doses of $0.75 \%$ glucose free ropivacaine for spinal anesthesia for lower limb and lower abdominal surgery. Kaohsiung J Med Sci 2004;20(9):423-30.

[12] Lee YY, Kee NWD, Chang HK, et al. Spinal ropivacaine for lower limb surgery: a dose response study. Anesth Analg 2007;105(2):520-3.

[13] Elzayyat NS, Nagy HIA, Girgis K. Comparing the effect of adding dexmedetomidine versus dexamethasone on prolonging the duration of intrathecal bupivacaine in lower abdominal operations. Ains-Shams J Anaesthesiol 2014;7(3):388-92.

[14] Biradar PA, Kaimar P, Gopalakrishna K. Effect of dexamethasone added to lidocaine in supraclavicular brachial plexus block: a prospective, randomised, double-blind study. Indian J Anaesth 2013;57(2):1804. 